\title{
The Social Structure of the City: A Critical Review of Contributing Sociologists
}

\section{Kamani Priyangika Mathotaarachchi, Karawita Arachchige Akalanka Nuwan Thilakarathna}

Institute of Human Resource Advancement, University of Colombo, Colombo, Sri Lanka

Email: akalanka@ihra.cmb.ac.lk

How to cite this paper: Mathotaarachchi, K. P., \& Thilakarathna, K. A. A. N. (2021). The Social Structure of the City: A Critical Review of Contributing Sociologists. Current Urban Studies, 9, 181-195. https://doi.org/10.4236/cus.2021.92011

Received: April 29, 2021

Accepted: May 21, 2021

Published: May 24, 2021

Copyright ( 2021 by author(s) and Scientific Research Publishing Inc. This work is licensed under the Creative Commons Attribution International License (CC BY 4.0).

http://creativecommons.org/licenses/by/4.0/

(c) (i) Open Access

\begin{abstract}
The idea of a city has changed over the course of human evolution and in modern times finding a definition as to what is exactly meant by a city has become a really difficult task. A city is signified not only by the structural differences it resembles something which is not accepted as a city for not having a physical built environment surrounded by concrete buildings and stagnation of office spaces, instead a city signifies a social reality and the interactions thereof, by which people come to differentiate a city from something which is not. This paper looks at the different definitions and ideologies brought forward by an urban sociologist in analysing the city while looking at the ecological, cultural and new urban sociological ideologies in defying and identifying the concept of a city.
\end{abstract}

\section{Keywords}

Urban Sociology, City, Globalization

\section{Introduction}

In urban sociology, the focus is on just one aspect of society, a certain kind of physical environment, how it is produced, and the social consequences that result. The premise of urban sociology is that urban environments have identifiable consequences regarding the ways that people experience themselves and others, the way they interact, and the way their lives are organized. Urban sociology is the field of scientific study that seeks to discover those systematic causes and effects.

One can enjoy similar physical environments and experience them in a number of different ways. That is, reality has a subjective side; we attach our own personal meaning to our experience of the world. The city or the urbanism has a different symbolic and emotional impact on different people. For example, people 
who have spent all of their years in the modern cities of London, New York or Tokyo will experience large cities in a different way from people in towns or villages since they measure and feel it in a different manner.

As cities grew rapidly in the nineteenth century and continued their unprecedented expansion in the next century, both the average person and the professional social observer struggled to make sense of the new environment-this new experiment in living that gathered millions onto a single patch of land. According to Berry, as late as 1900 , there were barely 43 cities in the world exceeding 500,000 population, of which only 16 exceeded 1,000,000. But since 1950, the number of large cities has increased very rapidly-close to 400 now exceed $1,000,000$ (Berry, 2008). Because urban growth of this sort was new and seemed to have infinite potential for continued expansion, many observers were awed and even fearful of the city's capacity for social disruption. In modern times, this is evident from the slums that exist along with picturesque buildings side by side, reminding us of the truth of urbanism, and in particular the gap between the rich and the poor (Flanagan, 2010). According to the United Nations (2012), sometime in early 2007, world urbanization crossed the $50 \%$ threshold, and for the first time in history, a majority of human beings lived in cities. By mid-century, the figure is projected to reach two-thirds. The future of humanity is clearly urban.

Urban sociology was produced by a sense of urgency, the recognition that cities were changing social life, and the desire to understand or predict the nature of those changes. Most early theoretical interpretations reflected that popular sense of urgency and tended to focus on the negative or disorganizing aspects of city living (KARP, 2015). Urban sociology emerged at the end of the nineteenth century at about the same time that sociology itself was achieving a greater measure of distinction among the social sciences.

The same features of the changing world provided the impetus for the development of both general sociological principles and for the development of a branch of social science devoted to the study of cities. The social consequences of the industrial revolution raised important philosophical questions about the future condition of humanity: foremost among these was the question of how the massing of people in cities would affect the social order. It was largely the growth of the eighteenth- and nineteenth-century city within the wider economic changes that were taking place in the world that fostered the development of sociology and encouraged the development of urban sociology in particular.

The creation of a specific field called urban sociology took place in Chicago in the early years of the twentieth century, which focused exclusively on urban spatial formations and change and the social behaviors emerging within this new environment. With urbanization becoming a dominant trend, foreign immigrant's as well domestic migrants from rural America flocked to U.S. cities (Niriella, 2012). Chicago was a prime destination. With the rapid and intense growth of the city, Chicago sociology observed the process of urbanization with wonder and awe. 
Urban sociology's distinguishing feature is its focus on the role of space in people's lives. It looks at the connection between urban and metropolitan spatial organization and the social and economic situations of different social groupspeople who vary by age, race, ethnicity, family type, country of origin, income, and socioeconomic status. Urban sociology embraces the diversity of social life and explores how it is played out across the physical contours of cities. It is also to be noted that, urban sociology is not the study of everything socially going on in cities, which ultimately, given the universality of the urban, would dominate the entire field of sociology. Urban sociology is about space-it is about land, development, housing, density, architecture, open space, distributions of land use, urban infrastructure, roads and transportation, neighborhood housing and population composition, and ultimately, location, location, location. Space, place, and its connection to people make up the study of urban sociology. Space literally and figuratively anchors the entire field (Shlay \& Balzarini, 2015).

In the above backdrop, the objective of this study is to critically comment on the contributions made by urban sociologist in explaining the nature and the definition of a city and how it has changed and evolved over the course of time. This paper contributes to the existing literature by bringing in new insights through colleting the ideas of different sociologists who have made a significant contribution towards the studying of the city.

This paper is divided in to several subsections, where the initial discussion is dedicated to explaining the nature and the historical evolution of the city, the next sections speak about the different approaches adopted at explaining the city, including the ideologies found upon, ecological, cultural and new urban studies. Then the discussion is shifted to globalization and the future of the city followed by the conclusion.

\section{The Nature and the Historical Evolution of the City}

In the earliest hieroglyphic script, the ideogram meaning "city" is a cross enclosed in a circle. The cross represents the convergence of routes bringing in men, merchandise and ideas: the circle is the moat or wall which physically binds the citizens together, emphasizing their distinctiveness. The argument for the distinctive quality of urban life is often illustrated by the adage from medieval Germany, "City air makes one free": the citizen had distinct rights not shared by plain countrymen and the city was distinguished by its separate institutional arrangements (Cahnman, 1966).

Savage and Warde tracing the historical evolution on the rise of "the city" states that, evolutionary approaches to urban development argued that the industrial city was the culmination of a long evolutionary process, stretching back to the earliest historical periods. Accordingly, two distinguished epochs were developed (Savage \& Warde, 1993). These were, first, "primordial urbanization" where settlements first emerged in the years between 15,000 BC and $4000 \mathrm{BC}$, as a collective form of organization additional to the usual migratory agricultural 
activities. The importance of the second period of "definitive urbanization", which began in Mesopotamia after 4000 BC, was that cities developed as fixed sites, in which "by means of its capacity to generate, store, and utilize social saving, the definitive city artefact is capable of transplanting itself out of its native uterine environments". This period of "definitive urbanization" is itself split into two epochs, before and after $1700 \mathrm{AD}$. In the first of these, cities were canters for a hinterland and existed in a stable hierarchy, in which hamlets formed a hinterland for villages, villages for towns, towns for cities, and cities for capital cities. Urban expansion was limited since cities were essentially parasitic on a limited agricultural economy. After 1700, the industrial city emerged as a dynamic force, able to increase in size because of the ability of economic production based in cities to sever their dependency on agriculture (Cahnman, 1966).

The industrial city was hence seen as the locus of the new industrial society and as ushering in a new period in history when urban growth could continue at a vastly expanded level. Yet since the 1930s the industrial societies which cities were seen to embody have themselves been transformed by de-industrialisationmanufacturing industries in many urban heartlands have collapsed; service industries have arisen and industrial production has developed in new, rural, areas, appearing to cut the apparently close connection between cities and industry on which the evolutionary ideas were based.

In the work of Simmel (Wolff, 1950) and the Chicago School cities represented the new and the modem, epitomes of the emergent economic and social order produced by industrial capitalism. They implicitly drew upon an evolutionary model of economic change. The city of Chicago, in particular, was taken as representative of the modem industrial city, and attempts to apply the concentric-ring model (developed by Burgess and modified by others) to other industrial cities were legion. Within this frame of thought the city was seen as the product of the elaborate division of labour characteristic of modem industrial society.

With the globalization becoming a reality and with the development of the ideas related to the concept of a global village, the concept of global cities has emerged. According to which, the traditional notions associated with the idea of a city has changed and new scholars like Saskia Sassen has advanced this idea of a global city. She argues that argued that large, technologically advanced urban areas defined the modern world (Sassen, 1991). This was particularly true with the development of telecommunication technologies and advancements in international trade and commerce, where certain cities like New York, London, Tokyo and recently Dubai has become prime examples for global cities, which tends to redefine the traditional notions attached to urbanization.

\section{What Is a City}

While urban sociology or the study of the city is a prolific topic of interest, one obvious thing that is lacking in its analysis is a globally recognized and well-defined notion of the term "city" itself. Chanman argues that, the mistake of character- 
izing cities in a preindustrial society by the deceptively simple notion that they have no industry entails the corresponding mistake of characterizing cities in an industrial society by the presence of industry. Consequently, with industry defined by the use of inanimate sources of power, the area around hydroelectric installations, such as the Grand Coulee Darn, would have to be considered a city. In view of this absurdity, one might have to fall back on the otherwise derided Wirthian characteristics of cities, that is, size, density, heterogeneity and individuation (Wirth, 1938). However, even the Wirthian definition is historically at fault. It combines universally observable ecological attributes of cities, namely size and density, and a likewise universally observable attribute, which is both ecological and sociological in nature, namely heterogeneity, with a clearly sociological and much more time-bound attribute, namely individuation.

On the same token it would also be wrong to characterize a city by the mere number of people, buildings, roads, infrastructure facilities or other physical attributes which are present in a given geographical area as a city since to do so would mean that where ever we find these things present it becomes a city and the social interactions present in such a context would not be studied to differentiate one from the other (i.e., urban areas from rural areas).

Max Weber's sociological model of the city as an independent territorial unit based on the inclusive loyalty of all its inhabitants contrasts sharply with the non-city, that is, a mono-cultural social unit exclusively based on kinship. It contrasts also with the statistical city, which is merely a relatively densely settled place of a certain size (Gianola, 2020). Max Weber in "The City" provided another definition of the city, where according to Weber, five attributes define an urban community: it must possess 1) a fortification, 2) a market, 3) a law code and court system of its own, 4) an association of urban citizenry creating a sense of municipal corporateness, and 5) sufficient political autonomy for urban citizens to choose the city's governors (Weber, 1958). The model Weber is using is twofold, taking its departure from the Greek polis and reaching its partial fulfilment in the commercial city of the high middle ages. The industrial city, which expands into the modern nation-state and which frequently takes on the aspect of an anomic city, must be seen as a deviant from the model. Such a city marks a proliferating late urban, or even post-urban, development, a far cry from the citizens' city of the thirteenth century, yet related to and comparable with it, inasmuch as it is oriented exclusively, or almost exclusively, on the utilization of market chances (Cahnman, 1966).

Emil Durkheim also tried to define the city in terms of his analysis of solidarity. He spoke of both organic and mechanical solidarity. The dichotomy between mechanical and organic solidarity demonstrates the fundamental shift in society which heralded the urban age, a process which is still taking place today in countries such as China, India and Nigeria. The city as a broad concept is a testament to organic solidarity, to the inter-dependency and cooperation required for it to function. It is within this organic mass of inter-dependent development 
that the modern city is born.

Tonnies spoke of "the city, where the general conditions of Gesellschaft prevail", and Durkheim submitted the proposition that "so long as the social organization is essentially segmentary towns do not exist" (KARP, 2015). When they have made use of the conceptual apparatus of Durkheim or of Tonnies, urban sociologists have paid little heed to the qualifications contained in such remarks; and they have characterized the city, often absolutely, in terms of Gesellschaft and organic solidarity. In this regard, they seem not to have recognized that the value of a concept is never realized solely from its application as a classificatory device. A concept is valuable to the extent that it facilitates the discrimination of empirical events so that the relationships among them may be better perceived and more adequately explained. Sociologists have used the terminology of Maine, Tonnies, and Durkheim to differentiate the character of urban living from that of rural existence and to detect the social consequences of urbanization.

Simmel's writings (Wolff, 1950) on the city may be viewed as a transitional link between the conceptual models provided by nineteenth-century sociologists and the observations of urban life made by sociologists at the University of Chicago in the early part of the twentieth century. Like Durkheim and Tonnies, the German sociologist Georg Simmel recognized the study of the historical transfiguration of social solidarity in Western civilization as a legitimate problem. Simmel's discussion of the metropolis and what might be termed the urban personality type cantered on the question of how the individual maintains his "existence against the sovereign powers of society" (in this case, forces exerted by the metropolitan environment). Such a question is obviously a significant one for a social psychology of urban life (Wolff, 1950).

According to Park and Burges, the city, from the point of view of this paper, is something more than a congeries of individual men and of social conveniences streets, buildings, electric lights, tramways, and telephones, etc.; something more, also, than a mere constellation of institutions and administrative devices-courts, hospitals, schools, police, and civil functionaries of various sorts. The city is, rather, a state of mind, a body of customs and traditions, and of the organized attitudes and sentiments that inhere in these customs and are transmitted with this tradition. The city is not, in other words, merely a physical mechanism and an artificial construction. It is involved in the vital processes of the people who compose it; it is a product of nature, and particularly of human nature (Mitchell, 2003).

Even with the above analysis it has to be concluded that, the idea of a city has changed over time and, while the definitions and explanations that have been provided explains some aspects of a city, on the same argument it can be seen that it fails to capture some of the others. Therefore, in defining what is a city has become a difficult deconstruct due to its changing nature and, the definition is provided to distinguish a city from another concept than to explain what a city 
comprises of.

\section{Ecological Approach in Analyzing the City}

As the early twentieth-century cities were taking and changing shape, some urban sociologists began to devote a large share of their work to an understanding of the morphology of cities. They developed predictive models in an attempt to identify a general pattern by which cities grew and changed. These early efforts resulted in the development of a subdiscipline of urban sociology known as urban ecology. The ecological approach to analyzing the city is attributable to the Chicago school in the United States who are considered as the pioneers of the study on American Urban Sociology. American urban sociology was initially formulated around the analysis of the city of Chicago, the great urban crossroads of the early twentieth century. As the Midwestern agro-industrial capital, Chicago was a transportation and trade gateway for foreign immigrants into the American heartland. Its status as a thriving international metropolis was established with its World's Columbian Exposition of 1893.

The city was a main node in the hub and spoke system of cities in the railroad era. An elevated train, the Loop, circled the downtown, boosting the significance of the urban center. The dominant center was significant to the theories of "human ecology" associated with the "Chicago School" of urban sociology, which Robert Park and his associates established at the University of Chicago beginning in 1913. It was actually Simmel who laid the foundation for the American ecological school which finally removed any discussion of economic conditions from urban sociology, and substituted ecology for the market economy accepted by both Tonnies and Simmel as the starting point for their discussions of urbanization (Banerjee, 2011).

The human ecologists applied ideas of Charles Darwin to the urban scene, justifying the presence of urban social inequality through comparison with the "struggle for existence" in the evolutionary life of plant and animal communities. Principles of "natural selection" explained the dominance of banks and corporations in the central business district (CBD), and dynamics of invasion-succession, now commonly identified as the gentrification and displacement process. It applied concepts of economics and market competition to the biological and social realm. The tradition of urban ecology tried to define the conditions of existence, within the city, of "natural areas" which, in the classic definition of Paul Hatt, were made up of two elements: 1) a spatial unit, limited by natural frontiers within which one finds a homogeneous population with a system of specific values; 2) a spatial unit inhabited by a population structured by internal symbolic relations. There is, therefore, a link between ecological frontiers and social characteristics at the very level of the definition of the urban unit.

Urban ecology is the study of the distribution and relationships among populations, services, industries, and open space in the urban arena. The ecological orientation is tied to Robert Park's interpretation of the forces that order urban 
space (Park \& Burgess, 1925). A contemporary of Park, R. D. McKenzie (McKenzie, 1924) catalogued the major features of the ecological framework, which included the following: tendencies toward area specialization and the segregation of dissimilar populations, centralization of services and activities that were most specialized or most in demand, along with the decentralization of nonspecialized services like grocery and drug stores, concentration as the result of concentrated patterns of commercial and industrial growth, along with tendencies toward dispersion as motor and electric transport grew in importance in contrast to steam locomotion (a formerly centralizing transportation technology), and invasion and succession-the processes whereby one segment of the urban population took possession of a specific urban territory from another.

While the ecological approach in explaining the structure of the city has been appraised by some, it also has its critics. The search for a general, predictive model has failed for a number of reasons. For one, ecological models were based on the premise that economic competition for space would ultimately determine the use to which an area is put. They did not take into account of the capacity of government to influence patterns through planning. Moreover, they failed to consider the potential role of sentiment, such as favouring the preservation of historic sites or open areas.

\section{Cultural Approach in Analyzing the City}

Culture is a powerful means of controlling cities. As a source of images and memories, it symbolizes "who belongs" in specific places. As a set of architectural themes, it plays a leading role in urban redevelopment strategies based on historic preservation or local heritage. With the disappearance of local manufacturing industries and periodic crises in government and finance, culture is more and more the business of cities-the basis of their tourist attractions and their unique, competitive edge. The growth of cultural consumption (of art, food, fashion, music, tourism) and the industries that cater to it fuels the city's symbolic economy, its visible ability to produce both symbols and space (Sacré, 2017).

Urban sociology's initial focus on culture and its connection to urban development began as a response that was seen as an overly deterministic model represented by urban ecology (Gottdiener, 2011). These early calls for assessing culture's role in urban spatial patterns argued that attitudes in the form of place-based attachments could counter the strongest economic forces. Nonetheless, culture was largely ignored within urban sociology as scholars sought to distance themselves from culture-of-poverty arguments that allegedly blamed the victims. Culture as a central variable within urban sociology became more prominent as a feature of the consumption of housing, goods, and services within cities. Culture is now theorized as a critical accompaniment to the dynamics of both local and global forces associated with gentrification.

In "The Cultural Role of Cities," Robert Redfield and Milton Singer tried to 
improve on all previous conceptions of the city, including the one Redfield had himself used in his folk-urban model, by emphasizing the variable cultural roles played by cities in societies. Redfield and Singer delineated two cultural roles for cities that all urban places perform, although with varying degrees of intensity and elaboration. Cities whose predominant cultural role is the construction and codification of the society's traditions perform "orthogenetic" functions. In such urban cultures, cadres of literati rationalize a "Great Tradition" of culture for the society at large. The cultural message emanating from Delhi, Paris, Washington, D.C., and other capitals of classic empires or modern nation-states functions to elaborate and safeguard cultural tradition (Redfield \& Singer, 1954). By contrast, cities whose primary cultural role is "heterogenetic," as Redfield and Singer defined it, are centres of technical and economic change, and they function to create and introduce new ideas, cosmologies, and social practices into the society. In cities like London, Marseille, or New York, the intelligentsia challenge old methods, question established traditions, and help make such cities innovative cultural centres.

Pioneer urban sociologist Sharon Zukin (Zukin, 1995) illustrated the demise of authenticity with the commodification of culture (and culture's corporate globalization) within gentrifying places. Culture is a market signal that attracts reinvestment and eventually global capital. Culture is a critical part of how urban space is commodified and transformed. In a very different way, culture is also connected to spatially concentrated poverty (Miles, 2007). Contemporary concentrated urban poverty is linked to a series of variables, including culture. But how culture is linked to the continuation of urban poverty is argued to be a complex phenomenon based on a combination of structural, spatial, and cultural variables. Those that connect culture to the spatial dynamics of poverty are careful to maintain that culture is not a determining factor of urban poverty but rather is an important feature of concentrated poverty

The writings of the sociologist Sharon Zukin focus on cities and the cultures of such cities. She argues, like Manuel Castells before her, that cities today are more focused on consumption than on production. Further consumption has taken on a life all its own. The cultures of cities have flourished in the post-industrial era. Art and architecture have blossomed, evident in the construction of new museums as well as public art (Stevenson, 2003). But in addition, cities have become enlivened by the variety of new cultural and ethnic groupings that have opened up a variety of new shops as well as restaurants all of which make the city a far more interesting, even spectacular place, than the older industrial cities.

\section{New Urban Sociology in Analyzing the City}

The new urban sociology emerged as a deliberate critique of urban ecology. It incorporates the role of power and politics in the guise of the state organizing urban development in the interests of capitalism. The new urban sociology embraces and adapts ideas of Marxist geographers like David Harvey and Neil 
Smith. Yet it asserts a role for human agency that often is missing from the more structural orientations of Marxist urbanism. It also retains urban ecology's focus on and belief in methods and research (McKeown, 1987).

With a genesis in community power structure research pioneered by Floyd Hunter, Harvey Molotch and later in collaboration with John Logan-explicitly introduced the role of power and politics, not ecological forces, in shaping urban development. The city as a growth machine thesis argues that the shape and direction of urban development, particularly of downtowns, is the product of behind-the-scenes land-based activities by locally based coalitions of urban actors who stand to benefit from increased land and property values, land use intensity, and population expansion. These institutional actors include corporations, utilities, newspapers, universities, and unions as well as government who work collectively and concertedly because of shared interests.

With the power to orchestrate local political decision making, growth coalition activities are magnets for public underwriting and subsidy. Although these developments yield significant economic advantages to coalition members, their public payoffs appear minimal or even harmful. The growth machine agenda holds sway because of a well-articulated and disseminated ideology that maintains that growth is in the public interest despite ample evidence to the contrary (MolotchSource, 1976). Popular acquiescence to growth machine projects is indicative of the hegemonic dominance of growth ideology. Contrary to urban ecology's insistence that cities are organized spatially according to processes that provide mutual benefits to all groups, the city as a growth machine stipulates that cities are a reflection of political, economic, and social manipulation and domination with clear winners and losers. Marxist geography informed a Marxist urban sociology and it often is difficult to disentangle the disciplinary differences.

David Harvey was the first to advocate for an urban political economy that explicitly links urban development to capitalism. Urban political economy focuses on how cities are involved in the circulation of capital and the reproduction of labor power. As part of capitalism's need to combat the falling rate of profit, cities also serve as the locale for collective consumption-that is, the construction of publicly funded urban infrastructure that supports capitalist enterprises, subsidizes profits, and assists labor force reproduction (Castells, 1976). Cities are not simply locations where capital is accumulated. Cities are an integral part of the capitalist accumulation process.

The physical expansion of cities reflects the use of cities to grow finance capital. Urban development and suburbanization are activities that require investment into the built environment. Urban development represents the shift of capital from manufactured commodities (the primary circuit of capital) to building homes and buildings (the secondary circuit of capital). Capital shifts between primary and secondary circuits reflect cycles of investment and disinvestment between these two circuits of capital (Harvey, 1973). 
Urban decline and uneven development in the form of abandonment and neighbourhood deterioration is not the absence of activity within these communities, but rather represent the active disinvestment of capital from communities. Reinvestment creates values while disinvestment removes it. Disinvestment is not simply a process in which buildings are neglected. Disinvestment devalues property as part of the process for later profitable revalorization. Urban political economy is the study of how capital accumulation actively develops and underdeveloped neighbourhoods, cities, and communities. The recognition of the crucial link between neighborhood vitality and housing finance led to many urban sociologists partnering with community-based organizations to fight neighborhood disinvestment (Cooke, 1990).

Urban political economy views cities as sites of production and capital accumulation (primary circuit of capital) and as places for consumption (the secondary circuit of capital) and for the reproduction of labor power (the generation of present and future labor market participants). Cities are an integral part of the reproduction of labor power by providing the physical environment in which labor power is recreated daily. But Manuel Castells (Castells, 1976) argued that cities are also sites for collective consumption i.e., publicly financed goods and services that are shared by urban residents. Collective consumption subsidizes the wage rate and increases capitalist profits therefore making city services a key factor in capitalist accumulation. In addition, different capacities of labor power are produced through the provision (or lack thereof) of education. Urban political economy implicates city services as mechanisms that create a stratified urban labor force. What is explicitly urban about collective consumption is that this occurs spatially (Brenner, 2009).

Much of the original theoretical work defining urban political economy focuses on the production of space. Under capitalism, this is the initial and subsequent work at turning land into a commodity and using it as a fundamental component of capitalist accumulation and labor force reproduction. Henri Lefebvre (Lefebvre, Writings on Cities, 1996), a French urban scholar and political activist, introduced the concept of production of space. The translation of his work was delayed, however, and so his direct contribution to the English-speaking world was mediated through the works of other urban Marxists (Castells, 1976).

According to Lefebvre (Lefebvre, The Production of Space, 1991) the ways in which space is produced is an integral part of the economic, political, and cultural dimensions of society. In the Production of Space, he argued that capitalist forces produce abstract space, that is, homogenized spaces that are turned into exchange values. The abstraction of space is how urban development is used to create exchange values under capitalism despite the reality that space or spaces are unique locations that never can be abstract. Space cannot be fully abstract because space operates as distinct social places that are constructed by people through their daily activities and lived experiences. These social spaces of use 
values are areas where the culture of urban life thrives, often in direct conflict with the abstract space idea generated by capitalism. People use-that is, produce-space to live. Capitalism produces space to raise money. These uses are in conflict.

Abstract space, like abstract labor is the means for capitalist appropriation. Just as labor power can be abstracted and sold on the labor market, abstract space permits the exchange of land as a commodity. But the problem for capitalist domination is that labor and space are unique. For Lefebvre this conflict over social and abstract space is the decisive class struggle, leading him to reject the legitimacy of property rights and to argue that urban inhabitants by virtue of their residency have the right to participate in all land use decisions and to appropriate space. This is the "right to the city" (Lefebvre, Writings on Cities, 1996).

Securitization (the trading of finance raised off of the exchange value of land) has increased the abstraction of space to the point that space itself is no longer featured in financial transactions (Harvey, 1973). This ultimate abstraction of space is its financialization in which land is produced through the sale of financial instruments, that are, at least in theory, attached to the land. Financialization represents land as a series of economic debts, obligations, and returns so that land in rural Idaho is rendered equivalent to land in New York City. The financialization of cities is an essential step for capitalist accumulation.

Urban theory's journey from urban ecology to urban political economy is one that continues to seek to explain urban development, neighborhood growth and decline, and their effects on people and their communities. It has moved its theoretical focus on explaining urban development away from ecological forces of self-selection. Urban political economy looks at the forces of capitalism-the commodification of land, the movement of capital into and out of the city's physical infrastructure, and the conflict for urban residents between property use and exchange values. Urban theory continues to look at large-scale forces that shape the urban scene. But contemporary urban theory also emphasizes the role of agency-his decision-making power of growth coalitions is about the behind-the-scenes activities of urban actors with shared interests. The power of urban growth coalitions, however, appears to be diminishing with the tidal forces associated with financialization-forces directly tied to decision making within global financial markets.

\section{Globalization and Global Cities}

The major contemporary world force is globalization. Globalization involves the development of mobile global capital and a global economic market, the integration of a global division of labor, the rise of transnational corporations, and the diminished importance of nation-states. Theorizing about a global order and cities is the major frontier for urban sociological theory. The focus of urban theory on globalization emphasizes a shift in how uneven development is addressed. Urban sociology initially addressed the uneven development within individual 
cities. With globalization, uneven development is a feature of the world. Urban development is expressed globally across an array of increasingly economically integrated cities.

Foreign direct investment in the global core, increased exchange between global financial markets, and the movement of industrial production from wealthier regions to poorer regions have corresponded with increased centralization of various firms and corporations that manage this increasingly complex and ever-growing system. As introduced by Saskia Sassen (Sassen, 1991) and others, global cities represent the "command and control centers" of the globally integrated economy. Global cities, such as New York, London, and Tokyo, among others, are the locations of the major global stock exchanges, the headquarters of transnational corporations, and world trade and lending organizations.

These organizations direct capital flows and investment and command institutional control of global resources and policy decisions, which make global cities the locus of power in an ever-globalizing world. The concept of globalizing urbanization focuses on how global forces are treated on the ground by local urban institutions and actors. Globalizing urbanization addresses how local urban development reflects international trends associated with heightened immigration, intensifying racial and ethnicity segregation, the spatial polarization of rich and poor, the incorporation of market mechanisms into public planning, widespread gentrification, and the growing specter of fiscal crises at every level of government. Theorizing about globalizing urbanization emphasizes local decision making tied to forces of globalization. This is because globalizing cities are the frontiers for the implementation for global trends, such as neoliberalism, and are sites for local resistance and acquiescence.

\section{The City: Where It Stands and What It Means for Tomorrow}

The above analysis of the sociological ideologies about the city encompasses the complexity of identifying the primal characteristics of the urbanism which can hold sway at any given moment in history. The city as it was founded in ancient times, demarcated by the city walls was characterized by the components it had in terms of its inhabitants and the physical structures. This conceptualization survived for millenniums and it changed with the uprising of the industrial revolution. With the rise of the industrial revolution, new cities emerged where factories and dwelling places were demarcated, where the living conditions of those who lived in the settlements were appalling. The city or urbanization was seen as a means of wealth accumulation and it was used as a device for subrogating the working class so as for the beneficial exploitation of the wealthy elites.

The system that was found under the industrial revolution changed with the two world wars and with the destruction of major cities, in particular the cities in European countries, the conceptualization of a city changed and with the rise of welfare state, the city was better planed and articulated so as to be more com- 
prehensive and at the same time to be more administrative friendly.

The scene changed again with the developments of communication technologies, international trade and in particular with the idea of globalization, the concept of city also developed to a concept of a "global city". This ideology, while being different from all the other conceptualizations that were presented at the explanation of a city, looks into more practical aspects as to what happens within the ideology of a city.

It has to be mentioned that the concept of city would move even further with new developments in space travel and development projects which at times tries to expand the livable area of the earth and with these new developments, the idea of a city would need to be re-developed and critiqued.

\section{Conclusion}

The concept of city has evolved through history and it still remains on the move. While failing to achieve a universal definition as such, the concept of a city itself has made people feel and experience certain places and physical environments in a different manner than the others. This clearly evidences the fact of the ideology that is inculcated in the minds of the people when they conceptualize the city. While the notion of a city has changed over time from a landscape demarcated by walls to becoming a place of exploitation to a place of cultural significance and most recently to an item of globalization, the ideology of a city as apart from something which is not, has helped the policy makers and governments alike in their development of the communities where urban planning has had been influenced and moved by the different perspectives that have been offered regarding the idea of a city.

While the sociological discourse on the idea of a city has been stuffed with many perspectives and ideologies, the city will always remain to mesmerize and evolve with the evolution of humanity itself and its end would not be possible of any predictions.

\section{Conflicts of Interest}

The authors declare no conflicts of interest regarding the publication of this paper.

\section{References}

Banerjee, T. (2011). Companion to Urban Design. London: Routledge. https://doi.org/10.4324/9780203844434

Berry, B. J. (2008). Urbanization. In J. M. Marzluff (Ed.), Urban Ecology (pp. 25-49). London: Springer. https://doi.org/10.1007/978-0-387-73412-5_3

Brenner, N. (2009). What Is Critical Urban Theory? City, 13, 198-207. https://doi.org/10.1080/13604810902996466

Cahnman, W. J. (1966). The Historical Sociology of Cities: A Critical Review. Social Forces, 45, 155-161. https://doi.org/10.2307/2574385 
Castells, M. (1976). The Urban Question. London: Edward Arnold.

Cooke, P. (1990). Modern Urban Theory in Question. Transactions of the Institute of British Geographers, 15, 331-343. https://doi.org/10.2307/622675

Flanagan, W. G. (2010). Urban Sociology: Images and Structure. Lanham, MD: Rowman \& Littlefield Publishers.

Gianola, D. (2020). City and Democracy in Max Weber. Topoi, 1-15. https://doi.org/10.1007/s11245-019-09687-w

Gottdiener, M. (2011). The New Urban Sociology. Boulder, CO: Westview Press.

Harvey, D. (1973). Social Justice and the City. Athens: University of Georgia Press.

Karp, D. A. (2015). Being Urban. Santa Barbara, CA: ABC-CLIO.

Lefebvre, H. (1991). The Production of Space. Malden, MA: Blackwell Publishing.

Lefebvre, H. (1996). Writings on Cities. Malden, MA: Blackwell Publishing.

McKenzie, R. D. (1924). The Ecological Approach to the Study of the Human Community. American Journal of Sociology, 30, 287-301. https://doi.org/10.1086/213698

McKeown, K. (1987). Marxist Political Economy and Marxist Urban Sociology. New York: Palgrave Macmillan. https://doi.org/10.1007/978-1-349-18567-2

Miles, M. (2007). Cities and Cultures. London: Routledge. https://doi.org/10.4324/9780203001097

Mitchell, D. (2003). The Right to the City. New York: Guilford Press.

MolotchSource, H. (1976). The City as a Growth Machine: Toward a Political Economy of Place. American Journal of Sociology, 82, 309-332. https://doi.org/10.1086/226311

Niriella, P. C. (2012). Sociological Explanation of City: A Theoretical Exploration. Saarbrücken: Lap Labmert.

Park, R. E., \& Burgess, E. W. (1925). The City. Chicago, IL: University of Chicago Press.

Redfield, R., \& Singer, M. B. (1954). The Cultural Role of Cities. Economic Development and Cultural Change, 3, 53-73. https://doi.org/10.1086/449678

Sacré, H. (2017). Cultural Approaches to Civic Learning in Urban Spaces. Cham: Springer.

Sassen, S. (1991). The Global City. Princeton, NJ: Princeton University Press.

Savage, M., \& Warde, A. (1993). Urban Sociology, Capitalism and Modernity. Hampshire: McMillan. https://doi.org/10.1007/978-1-349-22991-8

Shlay, A. B., \& Balzarini, J. (2015). Urban Sociology. In International Encyclopedia of the Social \& Behavioral Sciences (pp. 926-933). Oxford: Elsevier.

https://doi.org/10.1016/B978-0-08-097086-8.32164-X

Stevenson, D. (2003). Cities and Urban Cultures. Philadelphia, PA: Open University Press.

Weber, M. (1958). The City. New York: The Free Press.

Wirth, L. (1938). Urbanism as a Way of Life. The American Journal of Sociology, 44, 1-24. https://doi.org/10.1086/217913

Wolff, K. H. (1950). The Sociology of Georg Simmel. New York: The Free Press.

Zukin, S. (1995). The Cultures of Cities. Oxford: Blackwell Publishers Ltd. 